\title{
Clinical application of positron emission tomography in designing radiation fields in non-small cell lung cancer patients
}

\author{
ALEXANDER LIN $^{1}$, CHARLES WOOD ${ }^{1}$, CHRISTINE HILL-KAYSER ${ }^{1}$, \\ ROSEMARIE MICK ${ }^{2}$, LARRY KAISER ${ }^{3}$ and JAMES METZ ${ }^{1}$ \\ ${ }^{1}$ Department of Radiation Oncology, Hospital of the University of Pennsylvania; ${ }^{2}$ Department of Biostatistics and \\ Epidemiology, University of Pennsylvania School of Medicine, Philadelphia, PA 19104; \\ ${ }^{3}$ Department of Surgery, The University of Texas Health Science Center at Houston, Houston, TX 77225, USA
}

Received July 28, 2010; Accepted September 17, 2010

DOI: $10.3892 / \mathrm{etm} .2010 .153$

\begin{abstract}
There is significant interest in incorporating positron emission tomography (PET) into radiation therapy planning, although limited data exist that separately consider its diagnostic accuracy with respect to the primary tumor, hilum and mediastinum. This study evaluates the accuracy of PET planning by region of interest. Between January 2003 and July 2005, 351 patients with a pre-operative PET study underwent surgical resection. Of this population, 257 (73\%) patients with a diagnosis of non-small cell lung cancer were evaluated. PET study findings regarding the suspected primary tumor site, ipsilateral hilum and mediastinum were correlated with surgical pathology for determination of accuracy, sensitivity, specificity, positive predictive value (PPV) and negative predictive value (NPV). The accuracy of the primary site (95\%), ipsilateral hilum (80\%) and mediastinum (84\%) was relatively high. The NPV of the ipsilateral hilum and mediastinum was also high (92 and $86 \%$, respectively). However, the PPV of the ipsilateral hilum $(31 \%)$ and mediastinum $(75 \%)$ was lower. PET accuracy evaluating bronchoalveolar primary tumors was lower vs. other histologies (86 vs. $96 \%, \mathrm{p}=0.02$ ), although there was no difference with regard to the hilum or mediastinum. PET scanning may be an important tool in designing radiation treatment fields for lung cancer when combined with other imaging modalities. However, caution must be exercised when evaluating lymph node regions, as the PPV is not as high for the ipsilateral hilum and mediastinum as for the primary tumor. The NPV is high for nodal regions and may help with the exclusion of large treatment volumes in selected cases.
\end{abstract}

Correspondence to: Dr Alexander Lin, Department of Radiation Oncology, Hospital of the University of Pennsylvania, 3400 Spruce Street, 2 Donner Building, Philadelphia, PA 19104, USA

E-mail: alexander.lin@uphs.upenn.edu

Key words: lung cancer, radiation therapy, positron emission tomography

\section{Introduction}

Positron emission tomography (PET) continues to gain acceptance as a valuable tool in the diagnosis and staging of non-small cell lung cancer (NSCLC) (1-4). Its sensitivity and specificity with respect to the detection of malignancy in solitary pulmonary nodules have been estimated at 97 and $78 \%$, respectively (5), and PET has been shown to be superior to computed tomography (CT) in staging of the mediastinum (6-21). There has also been much interest in the incorporation of PET into radiation treatment planning, particularly with the opportunities afforded by 3-D conformal radiation therapy and intensity-modulated radiation therapy, which improve dose conformality and allow for dose escalation. The utilization of PET imaging in treatment planning could conceivably alter target volumes in two ways: exclusion of suspicious, but PET-negative, tissue volumes and inclusion of previously undetected tumor burden (22). Classically, target volumes in NSCLC include a combination of the primary site, with or without the ipsilateral hilum and/or mediastinum. While many studies have been conducted which evaluate the accuracy of PET in lung cancer, few have separated the data with respect to these areas, limiting the confidence with which PET can be employed in radiation planning. For this reason, this study was performed to evaluate the accuracy of PET imaging according to these regions of interest.

\section{Materials and methods}

A University of Pennsylvania Institutional Review Boardapproved retrospective study was undertaken to assess the diagnostic accuracy of PET based on surgical pathology confirmation. Between January 2003 and July 2005, 351 patients with suspicion of lung cancer underwent pre-operative PET imaging followed by surgical resection. The dates listed were based on the date of surgery, and all surgical procedures were performed at the Hospital of the University of Pennsylvania. From this population, 257 (73\%) patients with a pathologic diagnosis of NSCLC who did not undergo neoadjuvant therapy were assessed. Pre-operative clinical stage was estimated based on pre-operative PET and CT 


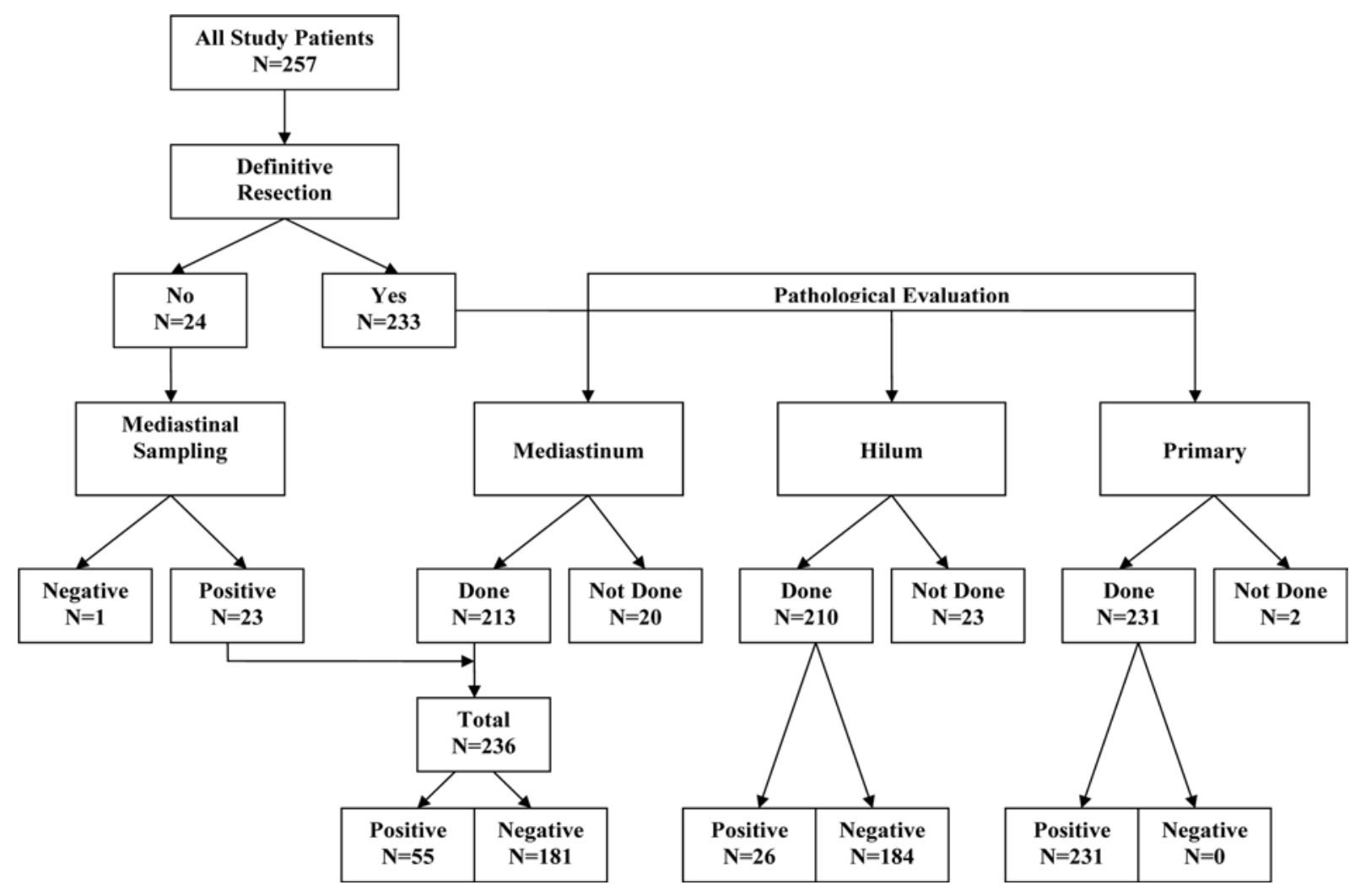

Figure 1. Pathology evaluation and findings.

imaging via the American Joint Committee on Cancer Staging System (6th edition) (23). Postoperative pathologic stage was based on surgical pathologic findings.

PET findings were documented separately with respect to the primary site, ipsilateral hilum and mediastinum. The PET results were then correlated with surgical pathology at the time of resection. Measures, including accuracy, sensitivity, specificity, positive predictive value (PPV) and negative predictive value (NPV), were determined. PET findings were scored as positive, suspicious or negative based solely on the original radiology report, and suspicious findings were ultimately considered positive as there would be a tendency to treat those regions of suspicion. A secondary radiology review of the original PET films was not conducted by the investigators, as it was decided to reflect utilization of PET reports and films in a typical radiation oncology clinic. PET studies were performed at both academic (30\%) and community $(70 \%)$ centers, and patients did not undergo combined PET/CT studies.

Statistical analysis. The $\chi^{2}(24)$ and Fisher's exact (24) tests were employed to test for associations of PET accuracy with clinical and surgical factors. All tests were two-sided, and statistical significance was defined as $\mathrm{p} \leq 0.05$. Concordance between clinical staging and pathologic staging was determined via a weighted Kappa statistic (24). Statistical analyses were performed with Statistical Package for Social Sciences statistical software (version 11.5 for Windows; SPSS Inc., Chicago, IL, USA) and StatXact statistical software (version 5.0 for Windows; Cytel Software Corporation, Cambridge, MA, USA).

\section{Results}

The characteristics of the patients included in the study are summarized in Table I. The median patient age was 68 years (range 35-86), and most presented with early clinical stage disease (63\% stage I and 14\% stage II). Similar numbers of males and females were included, and the majority of patients were Caucasian (90\%).

A diagram demonstrating the pathologic evaluation of the study patients is listed in Fig. 1. Nearly all patients underwent definitive surgical resection (91\%), with the remainder undergoing mediastinal sampling alone. The characteristics of the patients who underwent definitive resection are summarized in Table II. The median time between pre-operative PET and definitive resection was 41 days (range 2-333), and a majority of patients underwent lobectomy (77\%). Most tumors were either adenocarcinoma (45\%) or squamous cell carcinoma (30\%), and $92 \%$ of resected primary tumors were $>1 \mathrm{~cm}$ on pathologic measurement. Pre-operative clinical measurement of tumor diameter could not be documented, as primary tumor size was not always noted on the original radiology report.

The accuracy and prediction measures for the study patients with respect to PET imaging are shown in Table III. The accuracy of PET imaging was relatively high at the primary site (95\%), ipsilateral hilum (80\%) and mediastinum (84\%). Although the specificity of the hilum (84\%) and mediastinum (95\%) was likewise high, the sensitivity with regard to both was lower than the primary site (50 and 49\%, respectively, vs. 95\%). The specificity of the primary site was not evaluated, as all patients had pathologic evidence of 
Table I. Baseline clinical factors of all study patients $(n=257)$.

\begin{tabular}{|c|c|c|}
\hline Clinical factor & No. & $\%$ \\
\hline \multicolumn{3}{|l|}{ Gender } \\
\hline Male & 131 & 51 \\
\hline Female & 126 & 49 \\
\hline \multicolumn{3}{|l|}{ Age (years) } \\
\hline$\leq 65$ & 105 & 41 \\
\hline$>65$ & 152 & 59 \\
\hline Median (range) & $68(35-86)$ & \\
\hline \multicolumn{3}{|l|}{ Race } \\
\hline Caucasian & 232 & 90 \\
\hline Non-caucasian & 21 & 8 \\
\hline Unknown & 4 & 2 \\
\hline \multicolumn{3}{|l|}{ Clinical T stage } \\
\hline T0 & 3 & 1 \\
\hline $\mathrm{T} 1$ & 154 & 60 \\
\hline $\mathrm{T} 2$ & 78 & 30 \\
\hline $\mathrm{T} 3$ & 3 & 1 \\
\hline $\mathrm{T} 4$ & 19 & 7 \\
\hline \multicolumn{3}{|l|}{ Clinical N stage } \\
\hline N0 & 182 & 71 \\
\hline N1 & 34 & 13 \\
\hline $\mathrm{N} 2$ & 33 & 13 \\
\hline N3 & 8 & 3 \\
\hline \multicolumn{3}{|l|}{ Clinical stage } \\
\hline IA & 118 & 46 \\
\hline IB & 43 & 17 \\
\hline IIA & 17 & 7 \\
\hline IIB & 17 & 7 \\
\hline IIIA & 24 & 9 \\
\hline IIIB & 22 & 9 \\
\hline IV & 16 & 6 \\
\hline \multicolumn{3}{|l|}{ Primary tumor location } \\
\hline Left lung & 104 & 40 \\
\hline Right lung & 146 & 57 \\
\hline Not applicable/unknown & 7 & 3 \\
\hline
\end{tabular}

disease at the primary site. The negative prediction measures of the ipsilateral hilum (92\%) and mediastinum (86\%) were again high, but, as with sensitivity, the positive prediction measures of the ipsilateral hilum and mediastinum were lower (31 and 75\%, respectively). The PPV and NPV of the primary site were not calculated, as all patients had pathologic evidence of disease at the primary site.

Additionally, association tests were performed between PET accuracy and various clinical and pathologic factors. A comparison of PET accuracy with respect to bronchoalveolar tumors is shown in Table IV. There was decreased PET accuracy for bronchoalveolar primary tumors vs. other histologies (86 vs. 96\%, p=0.02), but no difference was noted with regards to accuracy within the ipsilateral hilum ( 85 vs. $79 \%, \mathrm{p}=0.64$ ) or mediastinum (94 vs. 85\%, p=0.27).

PET accuracy within the ipsilateral hilum and mediastinum in patients in whom PET accurately evaluated the primary tumor was compared to those in whom the primary
Table II. Characteristics of definitive resection patients $(n=233)$.

\begin{tabular}{lcr}
\hline & No. & $\%$ \\
\hline Time from CT/PET to surgery (days) & & \\
$\leq 30$ & 95 & 41 \\
$>30$ & 138 & 59 \\
Median (range) & $41(2-333)$ & \\
Surgical procedure & & \\
Pneumonectomy & 9 & 4 \\
Bilobectomy & 7 & 3 \\
Lobectomy & 180 & 77 \\
Wedge resection & 30 & 13 \\
Other & 7 & 3 \\
Pathologic primary tumor size (cm) & & \\
$\leq 1$ & 19 & 8 \\
$>1$ & 214 & 92 \\
Median (range) & $2.5(0.5-13.5)$ & \\
Histology & & \\
Squamous & 70 & 30 \\
Adenocarcinoma & 105 & 45 \\
Large cell & 9 & 4 \\
Bronchoalveolar & 36 & 16 \\
Poorly differentiated & 12 & 5 \\
Non-small cell & 1 & $<1$ \\
\hline
\end{tabular}

tumor was inaccurately evaluated. No difference was found in accuracy at either site. In the ipsilateral hilum, PET was accurate in $79 \%$ of patients with accurate PET at the primary site vs. $100 \%$ in those with false negative PET of the primary site $(\mathrm{p}=0.36)$. In the mediastinum, PET was accurate in $86 \%$ of patients with accurate PET at the primary site vs. $100 \%$ in those with false negative PET of the primary site $(p=0.61)$.

PET accuracy at the primary site was decreased in primary tumors $\leq 1 \mathrm{~cm}$ on pathologic evaluation vs. those $>1 \mathrm{~cm}$ (78 vs. $96 \%, \mathrm{p}=0.01)$, and there was no difference in PET accuracy at either the primary site (93 vs. $96 \%, \mathrm{p}=0.44)$, ipsilateral hilum ( 75 vs. $81 \%, p=0.44)$ or mediastinum ( 82 vs. $85 \%, p=0.73$ ) when comparing studies interpreted at academic centers $(n=42)$ vs. those interpreted at community facilities $(n=215)$.

Table V depicts concordance between clinical and pathologic staging of patients in the study. Thirty-five percent of patients were upstaged at surgery, $51 \%$ had no change in stage at surgery and $14 \%$ were downstaged at surgery. A weighted Kappa analysis demonstrated statistical concordance between clinical and pathologic staging $(\mathrm{p}<0.0001)$.

\section{Discussion}

Radiation treatment planning for lung cancer has evolved with the introduction of new diagnostic and imaging modalities and with increasing capacity for delivering conformal radiotherapy. Traditional radiation portals typically included the mediastinum and ipsilateral hilum electively, in addition to the primary tumor. Newer techniques omit elective coverage of the entire mediastinum and ipsilateral hilum, treating instead an 'involved field', which limits the treatment portals to only 
Table III. Accuracy and prediction measures of PET findings vs. pathology findings.

A, Correlation of PET to pathology findings by subsite.

\begin{tabular}{lrrr}
\hline & \multicolumn{3}{c}{ Pathology finding } \\
\cline { 2 - 4 } & + & - & Total \\
\hline Primary & & & \\
PET finding & & & \\
+ & 219 & 0 & 219 \\
- & 12 & 0 & 12 \\
Total & 231 & 0 & 231 \\
Hilum & & & \\
PET finding & & & \\
+ & 13 & 29 & 168 \\
- & 13 & 155 & 210 \\
Total & 26 & 184 & \\
Mediastinum & & & 36 \\
PET finding & & & 200 \\
+ & 27 & 172 & 236 \\
\hline- & 28 & 181 & \\
Total & 55 & &
\end{tabular}

B, Accuracy of PET by subsite.

\begin{tabular}{ccccc}
\hline Site & $\begin{array}{c}\text { PET accuracy } \\
\text { measure }\end{array}$ & $\begin{array}{c}\text { No. with } \\
\text { finding }\end{array}$ & $\begin{array}{c}\text { Total } \\
\text { no. }\end{array}$ \\
\hline
\end{tabular}

Primary $(n=231)$

$\begin{array}{crrr}\text { Sensitivity } & 219 & 231 & 94.8 \\ \text { Specificity } & 0 & 0 & \mathrm{NE}^{\mathrm{a}} \\ \text { Overall accuracy } & 219 & 231 & 94.8\end{array}$

Hilum $(n=210)$

$\begin{array}{crrr}\text { Sensitivity } & 13 & 26 & 50.0 \\ \text { Specificity } & 155 & 184 & 84.2 \\ \text { Overall accuracy } & 168 & 210 & 80.0\end{array}$

Mediastinum

$(n=236)$

\begin{tabular}{crrr} 
Sensitivity & 27 & 55 & 49.1 \\
Specificity & 172 & 181 & 95.0 \\
Overall accuracy & 199 & 236 & 84.3 \\
\hline
\end{tabular}

C, Predictive value of PET by subsite.

\begin{tabular}{ccccc}
\hline Site & $\begin{array}{c}\text { PET prediction } \\
\text { measure }\end{array}$ & $\begin{array}{c}\text { No. with } \\
\text { finding }\end{array}$ & $\begin{array}{c}\text { Total } \\
\text { no. }\end{array}$ & $\%$ \\
\hline
\end{tabular}

\begin{tabular}{lcrrr} 
Primary $(\mathrm{n}=231)$ & & & & \\
& PPV & 219 & 219 & $\mathrm{NE}^{\mathrm{a}}$ \\
& NPV & 0 & 12 & $\mathrm{NE}^{\mathrm{b}}$ \\
Hilum $(\mathrm{n}=210)$ & & & & \\
& PPV & 13 & 42 & 31.0 \\
& NPV & 155 & 168 & 92.3 \\
$\begin{array}{l}\text { Mediastinum } \\
(\mathrm{n}=236)\end{array}$ & & & & \\
& PPV & 27 & 36 & 75.0 \\
& NPV & 172 & 200 & 86.0 \\
\hline
\end{tabular}

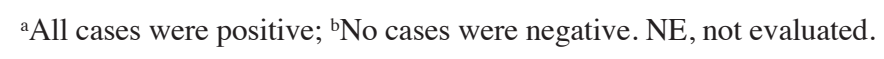

the primary tumor and nodal areas deemed to be positive on pre-treatment staging and evaluation. Single institution studies of involved field radiation suggest that elective nodal failures are rare, occurring in approximately $6 \%$ of patients $(25,26)$; this may lead to the underestimation of the true incidence of elective nodal relapse, as isolated nodal relapses are rare and nodal relapses in the setting of hematogenous metastases are typically excluded. A phase III randomized trial of 200 patients (in whom staging did not include PET) comparing elective nodal radiation and involved field radiation demonstrated no difference in overall survival between the groups at 5 years (27). However, a potential limitation of involved field radiation is in the accuracy of staging and diagnostic studies to detect pathologic disease. PET is a modality which might provide such enhanced target delineation. While the role of PET or PET/CT in addition to conventional workup to prevent unnecessary surgery has been previously studied in randomized trials (28-30), the role of PET in radiation field design is an equally relevant, yet less examined, issue. This study sought to evaluate PET imaging by region of interest as it applies to radiation treatment planning in NSCLC.

To our knowledge, the present study constitutes one of the largest published series comparing PET to surgical pathologic data. We analyzed PET accuracy at several distinct sites relevant for radiation treatment planning: primary tumor, ipsilateral hilum and mediastinum. We found a relatively high overall accuracy of PET with regard to staging of the primary site $(95 \%)$, ipsilateral hilum $(80 \%)$ and mediastinum (84\%), which is similar to other published series investigating PET-based staging and higher than the accuracy rates obtained with CT staging $(17,18,20,21)$. Even with bronchoalveolar tumors, where PET demonstrated decreased accuracy and instances where the primary site was inaccurately evaluated, PET retained a high accuracy in the ipsilateral hilum and mediastinum. This supports the use of PET in combination with other imaging and staging modalities as a potentially important tool for radiation field design.

The specificity and negative predictive values associated with PET evaluation of nodal regions from our study were relatively high. These findings could be utilized in deciding to treat with involved field radiation techniques, excluding large, elective treatment volumes in selected cases. Conversely, the sensitivity and positive predictive values noted in our study were relatively low; however, these results should be interpreted with caution and may simply reflect the smaller numbers of patients with positive hilar and mediastinal disease, as the majority had early stage disease.

It is important to note that clinical and pathologic stage were in agreement only half of the time, with $35 \%$ of patients being upstaged at the time of surgery. Previous studies have reported a level of agreement between 35 and 55\% for clinical and pathologic staging (31-35), with deterioration in agreement as stage increases (31). Subclinical, microscopic disease, not visualized on CT or PET, often accounts for this upstaging. Nomori et al (16), in a study of 80 patients comparing preoperative PET and CT vs. surgical pathology, found that PET was unable to distinguish foci of disease less than $4 \mathrm{~mm}$ and that $32 \%$ of all resected lymph nodes with disease involvement had foci of disease less than $4 \mathrm{~mm}$. The presence of subclinical disease involvement illustrates the limitations of clinical 
Table IV. PET overall accuracy for bronchoalveolar tumors vs. other histologies.

\begin{tabular}{|c|c|c|c|c|c|}
\hline \multirow[b]{3}{*}{ Site } & \multicolumn{2}{|c|}{ Brochoalveolar } & \multicolumn{2}{|c|}{ Other histologies } & \multirow[b]{3}{*}{ P-value } \\
\hline & \multicolumn{2}{|c|}{ Pathology } & \multicolumn{2}{|c|}{ Pathology } & \\
\hline & + & - & + & - & \\
\hline \multicolumn{6}{|l|}{ Primary } \\
\hline $\mathrm{PET}^{+}$ & 31 & 0 & 188 & 0 & \\
\hline PET $^{-}$ & 5 & 0 & 7 & 0 & \\
\hline Accuracy & \multicolumn{2}{|c|}{$31 / 36(86 \%)$} & \multicolumn{2}{|c|}{$188 / 195(96 \%)$} & 0.02 \\
\hline \multicolumn{6}{|l|}{ Hilum } \\
\hline $\mathrm{PET}^{+}$ & 0 & 4 & 13 & 25 & \\
\hline PET $^{-}$ & 1 & 28 & 12 & 127 & \\
\hline Accuracy & \multicolumn{2}{|c|}{ 28/33 (85\%) } & \multicolumn{2}{|c|}{ 140/177 (79\%) } & 0.64 \\
\hline \multicolumn{6}{|c|}{ Mediastinum } \\
\hline $\mathrm{PET}^{+}$ & 0 & 1 & 12 & 8 & \\
\hline PET $^{-}$ & 1 & 30 & 19 & 142 & \\
\hline Accuracy & \multicolumn{2}{|c|}{$30 / 32(94 \%)$} & \multicolumn{2}{|c|}{$154 / 181(85 \%)$} & 0.27 \\
\hline
\end{tabular}

Table V. Concordance between clinical and pathologic staging.

A, Comparison between clinical and pathologic stage.

\begin{tabular}{|c|c|c|c|c|c|c|}
\hline \multirow[t]{2}{*}{ Clinical stage } & \multicolumn{6}{|c|}{ Pathologic stage } \\
\hline & IA $(n=67)$ & IB $(n=57)$ & $\mathrm{IIA}+\mathrm{IB}(\mathrm{n}=34)$ & IIIA $(n=27)$ & IIIB $(n=18)$ & IV $(n=12)$ \\
\hline IA $(n=108)$ & 56 & 19 & 15 & 3 & 9 & 6 \\
\hline IB $(n=42)$ & 2 & 26 & 5 & 6 & 3 & 0 \\
\hline $\mathrm{IIA}+\mathrm{IIB}(\mathrm{n}=31)$ & 5 & 7 & 12 & 7 & 0 & 0 \\
\hline IIIA (n=13) & 0 & 3 & 0 & 7 & 1 & 2 \\
\hline IIIB (n=13) & 3 & 1 & 2 & 3 & 4 & 0 \\
\hline IV $(n=8)$ & 1 & 1 & 0 & 1 & 1 & 4 \\
\hline
\end{tabular}

$\mathrm{B}$, Change in staging based on operative findings.

Pathologic vs. clinical staging

No.

$\uparrow$ Stage

Pathologic stage $>$ clinical stage (to the right of the bold area)

$=$ Stage

Pathologic stage $=$ clinical stage $($ bold area $)$

$\downarrow$ Stage

Pathologic stage < clinical stage (below bold area)

Weighted Kappa $=0.36(95 \%$ CI 0.21-0.50); p<0.0001.

staging in NSCLC, especially in those treated with definitive radiation therapy. The use of involved field radiation, with target delineation based on PET and CT alone, could therefore potentially lead to erroneous underdosing or non-treatment of microscopic disease foci. Incorporation of pathologic assessment of lymph nodes, via mediastinoscopy or endobronchial ultrasound, in addition to conventional staging with imaging and PET, may improve the overall accuracy of staging and further assist in radiation treatment planning.

There are strengths and limitations to the present study. More than three-quarters of the patients had clinical stage I or II disease, which may account for the lower than expected sensitivity and PPV for PET detection of lymph node involvement. Further evaluation of PET accuracy in more advanced 
stage patients is warranted, as this would better reflect the typical lung cancer patient referred for definitive radiation therapy. Additionally, this study focused specifically on the role of PET alone, whereas PET/CT is now more commonly used for staging. Despite these limitations, our results constitute one of the largest collected series on PET staging, and the study presented here is one of the few examining accuracy by specific disease subsites. In addition, our findings that there was no compromise in accuracy of lymph node staging, even with bronchoalveolar histology or when PET inaccurately staged the primary site, are novel to our knowledge.

In conclusion, PET is a useful tool in the clinical assessment and staging of lung cancer, and should be incorporated as part of standard staging. With respect to radiation treatment planning, it is helpful in delineating disease-affected sites and in determining which areas to incorporate and which to exclude in the radiation portals. However, given the rates of upstaging observed between clinical and pathologic staging and the risk of subclinical disease involvement, caution must be exercised during the delineation of limited fields, and pathologic assessment of nodes should be performed whenever possible. Lung cancer remains one of the most common causes of cancer-related death in both men and women, and local failure is a common occurrence. Refinements in target delineation, radiation planning and delivery are potential avenues by which outcomes may be improved, which will ultimately require the incorporation of multimodal staging evaluations, including PET.

\section{Acknowledgements}

The authors would like to acknowledge Dr Eli Glatstein for his continuing guidance and mentorship, without which this manuscript would not have been possible.

\section{References}

1. Albes JM, Lietzenmayer R, Schott U, Schülen E, Wehrmann M and Ziemer G: Improvement of non-small-cell lung cancer staging by means of positron emission tomography. Thorac Cardiovasc Surg 47: 42-47, 1999.

2. Bury T, Paulus P, Dowlati A, Corhay JL, Weber T, Ghaye B, Schoffers J, Limet R, Albert A, Rigo P and Radermecker M: Staging of the mediastinum: value of positron emission tomography imaging in non-small cell lung cancer. Eur Respir J 9: 2560-2564, 1996.

3. Coleman RE: PET in lung cancer. J Nucl Med 40: 814-820, 1999.

4. Sachs S and Bilfinger TV: The impact of positron emission tomography on clinical decision making in a university-based multidisciplinary lung cancer practice. Chest 128: 698-703, 2005.

5. Gould MK, Maclean CC, Kuschner WG, Rydzak CE and Owens DK: Accuracy of positron emission tomography for diagnosis of pulmonary nodules and mass lesions: a metaanalysis. JAMA 285: 914-924, 2001.

6. Gould MK, Kuschner WG, Rydzak CE, Maclean CC, Demas AN, Shigemitsu H, Chan JK and Owens DK: Test performance of positron emission tomography and computed tomography for mediastinal staging in patients with non-small-cell lung cancer: a meta-analysis. Ann Intern Med 139: 879-892, 2003.

7. Toloza EM, Harpole L and McCrory DC: Noninvasive staging of non-small cell lung cancer: a review of the current evidence. Chest 123: S137-S146, 2003.

8. Sasaki M, Ichiya Y, Kuwabara Y, Akashi Y, Yoshida T, Fukumura T, Murayama S, Ishida T, Sugio K and Masuda K: The usefulness of FDG positron emission tomography for the detection of mediastinal lymph node metastases in patients with non-small cell lung cancer: a comparative study with X-ray computed tomography. Eur J Nucl Med 23: 741-747, 1996.
9. Sazon DA, Santiago SM, Soo Hoo GW, Khonsary A, Brown C, Mandelkern M, Blahd W and Williams AJ: Fluorodeoxyglucosepositron emission tomography in the detection and staging of lung cancer. Am J Respir Crit Care Med 153: 417-421, 1996.

10. Vansteenkiste JF and Stroobants SG: The role of positron emission tomography with 18F-fluoro-2-deoxy-D-glucose in respiratory oncology. Eur Respir J 17: 802-820, 2001.

11. Valk PE, Pounds TR, Hopkins DM, Haseman MK, Hofer GA, Greiss HB, Myers RW and Lutrin CL: Staging non-small cell lung cancer by whole-body positron emission tomographic imaging. Ann Thorac Surg 60: 1573-1582, 1995.

12. Vansteenkiste JF, Stroobants SG, De Leyn PR, Dupont PJ, Bogaert J, Maes A, Deneffe GJ, Nackaerts KL, Verschakelen JA, Lerut TE, Mortelmans LA and Demedts MG: Lymph node staging in non-small-cell lung cancer with FDG-PET scan: a prospective study on 690 lymph node stations from 68 patients. J Clin Oncol 16: 2142-2149, 1998.

13. Patz EF Jr, Lowe VJ, Goodman PC and Herndon J: Thoracic nodal staging with PET imaging with 18FDG in patients with bronchogenic carcinoma. Chest 108: 1617-1621, 1995.

14. Pieterman RM, van Putten JW, Meuzelaar JJ, Mooyaart EL, Vaalburg W, Koëter GH, Fidler V, Pruim J and Groen HJ: Preoperative staging of non-small-cell lung cancer with positronemission tomography. N Engl J Med 343: 254-261, 2000.

15. Scott WJ, Gobar LS, Terry JD, Dewan NA and Sunderland JJ: Mediastinal lymph node staging of non-small-cell lung cancer: a prospective comparison of computed tomography and positron emission tomography. J Thorac Cardiovasc Surg 111: 642-648, 1996.

16. Nomori H, Watanabe K, Ohtsuka T, Naruke T, Suemasu K and Uno K: The size of metastatic foci and lymph nodes yielding false-negative and false-positive lymph node staging with positron emission tomorgraphy in patients with lung cancer. J Thorac Cardiovasc Surg 127: 1087-1092, 2004.

17. Steinert HC, Hauser M, Allemann F, Engel H, Berthold T, von Schulthess GK and Weder W: Non-small cell lung cancer: nodal staging with FDG PET versus CT with correlative lymph node mapping and sampling. Radiology 202: 441-446, 1997.

18. Wahl RL, Quint LE, Greenough RL, Meyer CR, White RI and Orringer MB: Staging of mediastinal non-small cell lung cancer with FDG PET, CT, and fusion images: preliminary prospective evaluation. Radiology 191: 371-377, 1994.

19. Hagberg RC, Segall GM, Stark P, Burdon TA and Pompili MF: Characterization of pulmonary nodules and mediastinal staging of bronchogenic carcinoma with F-18 fluorodeoxyglucose positron emission tomography. Eur J Cardiothorac Surg 12: 92-97, 1997.

20. Gupta NC, Tamim WJ, Graeber GG, Bishop HA and Hobbs GR: Mediastinal lymph node sampling following positron emission tomography with fluorodeoxyglucose imaging in lung cancer staging. Chest 120: 521-527, 2001.

21. Dunagan D, Chin R Jr, McCain T, Case L, Harkness B, Oaks T and Haponik E: Staging by positron emission tomography predicts survival in patients with non-small cell lung cancer. Chest 119: 333-339, 2001.

22. Lavrenkov K, Partridge M, Cook G and Brada M: Positron emission tomography for target volume definition in the treatment of non-small cell lung cancer. Radiother Oncol 77: 1-4, 2005.

23. Greene FL: American Joint Committee on Cancer, American Cancer Society. AJCC Cancer Staging Manual. 6th edition. Springer-Verlag, New York, 2002.

24. Fleiss JL: Statistical Methods for Rates and Proportions. 2nd edition. John Wiley and Sons, Inc., New York, 1981.

25. Bradley JD, Wahab S, Lockett MA, Perez CA and Purdy JA: Elective nodal failures are uncommon in medically inoperable patients with stage I non-small-cell lung carcinoma treated with limited radiotherapy fields. Int J Radiat Oncol Biol Phys 56: 342-347, 2003.

26. Rosenzweig KE, Sura S, Jackson A and Yorke E: Involved-field radiation therapy for inoperable non small-cell lung cancer. J Clin Oncol 25: 5557-5561, 2007.

27. Yuan S, Sun X, Li M, Yu J, Ren R, Yu Y, Li J, Liu X, Wang R, Li B, Kong L and Yin Y: A randomized study of involved-field irradiation versus elective nodal irradiation in combination with concurrent chemotherapy for inoperable stage III nonsmall cell lung cancer. Am J Clin Oncol 30: 239-244, 2007.

28. Van Tinteren H, Hoekstra OS, Smit EF, van den Bergh JH, Schreurs AJ, Stallaert RA, van Velthoven PC, Comans EF, Diepenhorst FW, Verboom P, van Mourik JC, Postmus PE, Boers $\mathrm{M}$ and Teule GJ: Effectiveness of positron emission tomography in the preoperative assessment of patients with suspected non-small-cell lung cancer: the PLUS multi-centre randomized trial. Lancet 359: 1388-1393, 2002. 
29. Viney RC, Boyer MJ, King MT, Kenny PM, Pollicino CA McLean JM, McCaughan BC and Fulham MJ: Randomized controlled clinical trial of the role of positron emission tomography in the management of stage I and II non-small-cell lung cancer. J Clin Oncol 22: 2357-2362, 2004.

30. Fischer B, Lassen U, Mortensen J, et al: Preoperative staging of lung cancer with combined PET-CT. N Engl J Med 361: 32-39, 2009.

31. López-Encuentra A, García-Luján R, Rivas JJ, RodríguezRodríguez J, Torres-Lanza J, Varela-Simo G; Bronchogenic Carcinoma Cooperative Group of the Spanish Society of Pneumology and Thoracic Surgery: Comparison between clinical and pathologic staging in 2,994 cases of lung cancer. Ann Thorac Surg 79: 974-979, 2005.

32. Fernando HC and Goldstraw P: The accuracy of clinical evaluative intrathoracic staging in lung cancer as assessed by postsurgical pathologic staging. Cancer 65: 2503-2506, 1990.
33. Gdeedo A, van Schil P, Corthouts B, van Mieghem F, van Meerbeeck $J$ and van Marck E: Comparison of imaging TNM [(i)TNM] and pathological TNM [pTNM] in staging of bronchogenic carcinoma. Eur J Cardiothorac Surg 12: 224-227, 1997.

34. Bülzebruck H, Bopp R, Drings P, Bauer E, Krysa S, Probst G, van Kaick G, Müller KM and Vogt-Moykopf I: New aspects in the staging of lung cancer. Prospective validation of the International Union Against Cancer TNM classification. Cancer 70: 1102-1110, 1992.

35. Bülzebruck H, Drings P, Kayser K, Schulz V, Tuengerthal S and Vogt-Moykopf I: Classification of lung cancer: first experiences with the new TNM classification (4th edition). Eur Respir J 4: 1197-1206, 1991. 